Check for updates

Cite this: RSC Adv., 2017, 7, 28837

Received 31st March 2017

Accepted 25th May 2017

DOI: $10.1039 / \mathrm{c7ra03742b}$

rsc.li/rsc-advances

\section{Cell-free protein synthesis of norovirus virus-like particles $\dagger$}

\author{
Jiayuan Sheng, ${ }^{a}$ Shaohua Lei, ${ }^{\mathrm{b}}$ Lijuan Yuan ${ }^{\mathrm{b}}$ and Xueyang Feng (D) *a \\ Norovirus vaccine development largely depends on recombinant virus-like-particles (VLPS). Norovirus VLPS \\ have been produced in several cell-based expression systems with long production times. Here we report, \\ for the first time, that norovirus VLPs can be expressed and assembled by using a cell-free protein \\ expression system within four hours.
}

Human noroviruses (HuNoVs) are the most common cause of viral gastroenteritis in humans. ${ }^{1}$ The first and only $\mathrm{HuNoV}$ vaccine candidate under human clinical trial (developed by Takeda Pharmaceutical Co. Ltd $^{2}$ ) contains VLP antigens, which are particles that mimic the native protein capsid of HuNoV. Because HuNoVs could hardly replicate in traditional tissue culture, ${ }^{3,4}$ several other cell-based expression systems have been used for the production of HuNoV-VLPs, including E. coli, ${ }^{5} P$. pastoris ${ }^{3}$ insect cells ${ }^{6}$ and plants. ${ }^{7,8}$ When using the E. coli-based expression system, a capsid protein of HuNoV-VLPs fused with GST (glutathione S-transferase) could only be synthesized at a yield of 1.5-3 $\mathrm{mg} \mathrm{L}^{-1},{ }^{5}$ which is too low to meet the demands of producing HuNoV-VLPs as vaccines. When using an insectbased expression system, HuNoV-VLPs could be produced at $0.1 \mathrm{~g} \mathrm{~L}^{-1}$. However, the protein purification of insect-cell based HuNoV-VLPs is often complex ${ }^{9}$ and the insect cells themselves grow very slowly (18-24 h per division), representing grand challenges for large-scale production of HuNoV-VLPs. Currently, the $P$. pastoris-based expression system is arguably the best cell-based platform for the production of HuNoV-VLPs because HuNoV-VLPs could be synthesized at high yield $(0.6 \mathrm{~g}$ $\mathrm{L}^{-1}$ ) and the growth rate of $P$. pastoris (doubling time is $\sim 90$ min) is faster than insect cells.

An alternative approach to produce VLPs is the cell-free protein synthesis (CFPS) system ${ }^{\mathbf{1 0 , 1 1}}$ that expresses recombinant protein in vitro without the use of living cells. The CFPS system uses crude cell extracts to supply all the necessary elements for transcription, translation, and protein folding, ${ }^{12,13}$ including ribosomes, aminoacyl-tRNA synthetases, translation initiation and elongation factors, ribosome release factors, metabolic enzymes, chaperones, and foldases. By supplementing the recombinant DNA encoding the target protein as the

${ }^{a}$ Department of Biological Systems Engineering, Virginia Polytechnic Institute and State University, Blacksburg, VA 24061,USA.E-mail: xueyang@vt.edu

${ }^{b}$ Department of Biomedical Sciences and Pathobiology, Virginia Polytechnic Institute and State University, Blacksburg, VA 24061, USA

$\dagger$ Electronic supplementary information (ESI) available. See DOI: 10.1039/c7ra03742b template and the other essential substrates such as amino acids, nucleotides, energy substrates, cofactors, and salts, hundreds of active biological catalysts within the cell lysate will act as a chemical factory to synthesize and fold the target proteins. ${ }^{\mathbf{1 4 , 1 5}}$ The CFPS system offers several advantages over conventional cell-based protein expression systems in producing the protein antigens. First, the CFPS system is time saving since it produces proteins directly from a PCR fragment or an mRNA template without the need for molecular cloning, and bypasses time-consuming cell culturing. ${ }^{16}$ Second, the CFPS system achieves arguably the highest yields for numerous proteins, from hundreds of micrograms per millilitre to milligrams per millilitre in a batch reaction. For example, CFPS was recently used to synthesize botulinum toxins (as vaccine candidates) at more than $1 \mathrm{~g} \mathrm{~L}^{-1} \cdot{ }^{17,18}$ Third, the CFPS system bypasses the cytotoxicity issue and is able to produce proteins that are normally toxic to cells. ${ }^{19}$

In this study, we reported for the first time that an E. colibased CFPS system could be used to synthesize and assemble HuNoV-VLPs in 4 hours (Fig. 1A). To prepare the CFPS system, two types of S30 extract, the BL21 S30 extract and the CK-T7 extract, were used. The BL21 S30 extract was prepared from the E. coli strain BL21 as previously reported. ${ }^{20}$ The CK-T7 extract was used to bypass the exogenous addition of commercial creatine kinase (CK) and T7 RNA polymerase (T7 RNAP) into the cell-free reaction mixtures. To prepare the CK-T7 extract, a recombinant $E$. coli $\mathrm{BL} 21$ strain was constructed by harbouring a CK and T7 RNAP expression vector pETDuet-CK-T7. The CK and T7 RNAP were expressed during the cultivation of E. coli via IPTG induction $(1.0 \mathrm{mM})$ at $\mathrm{OD}_{600} 0.5$. The recombinant $E$. coli BL21 strains were harvested at $2 \mathrm{~h}$ after induction and used for preparing the CK-T7 extract. In addition to the $\mathrm{S} 30$ extracts, we also prepared the CFPS reaction mix consisted of the following components in a total volume of $50 \mu \mathrm{L}$ : $55 \mathrm{mM}$ HEPES/KOH, pH 7.5, $1.2 \mathrm{mM}$ ATP, $0.85 \mathrm{mM}$ each of GTP, UTP,

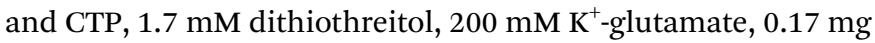
$\mathrm{mL}^{-1}$ E. coli total tRNA, $34 \mathrm{mg} \mathrm{mL}^{-1}$ folinic acid, $0.65 \mathrm{mM}$ cAMP, $2 \mathrm{mM}$ each of amino acids, $80 \mathrm{mM}$ creatine phosphate, $28 \mathrm{mM}$ ammonium acetate, $11 \mathrm{mM}$ magnesium acetate, $18 \mu \mathrm{L}$ 

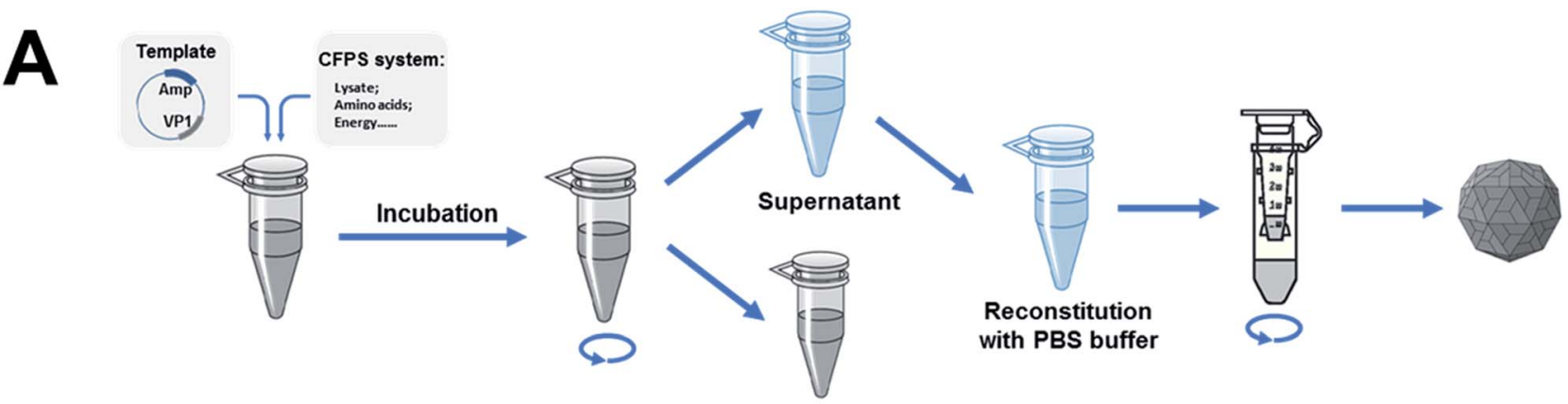

Precipitate

Expression (3 h)

Pretreatment (15 min)

Reconstitution and Assemble (30 min)

\section{Norovirus GIl type 3}

B

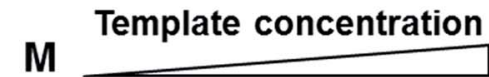

NC PC
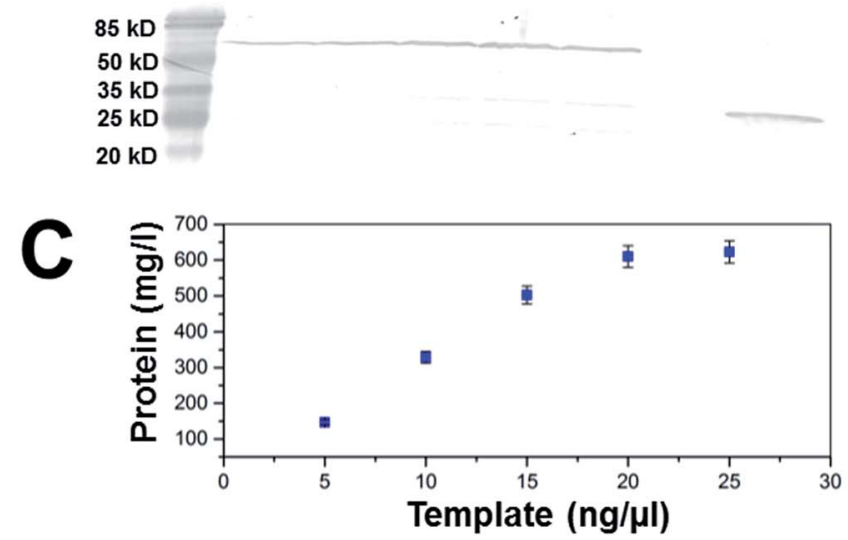

D

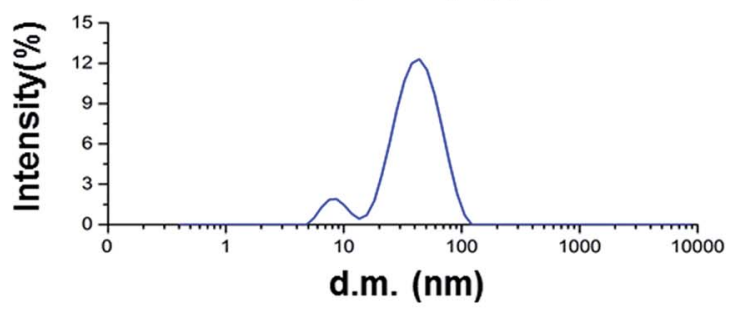

E

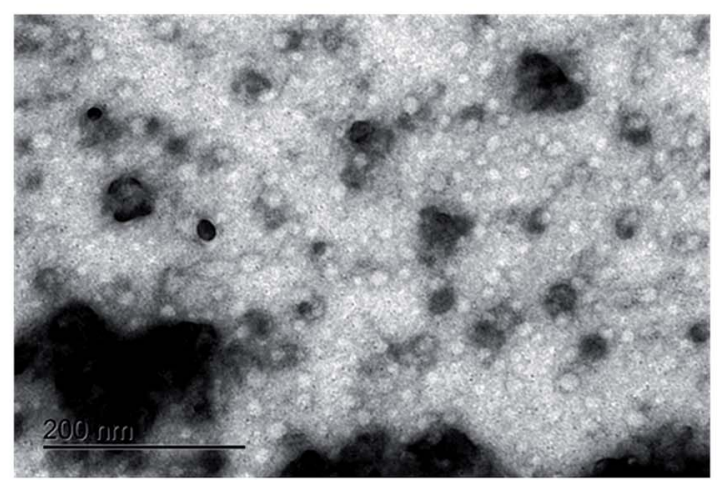

\section{Norovirus GIl type 4}
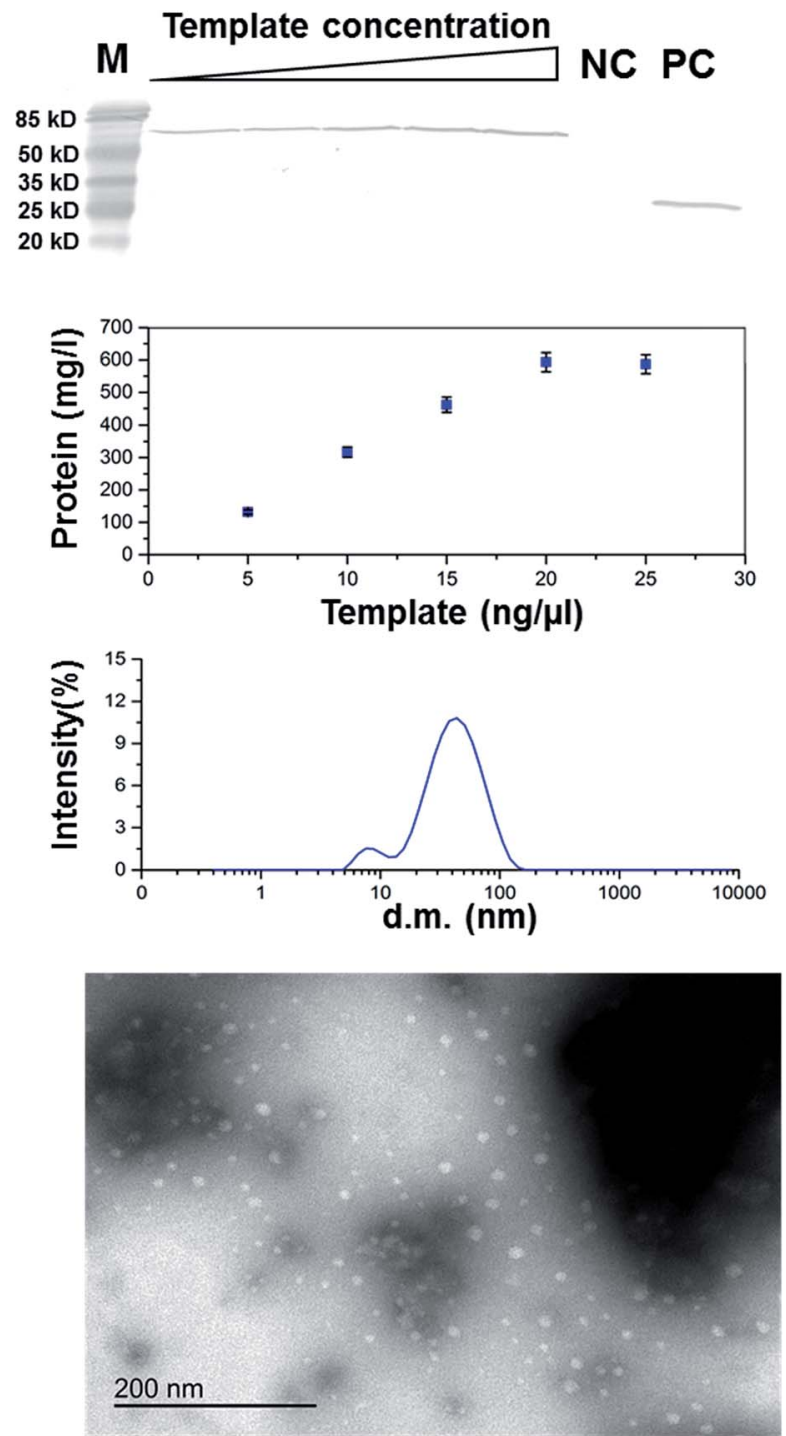

Fig. 1 (A) Flow-chart of HuNoV-VLP expression by using CFPS system. The entire process of VLP production and assembly was finished within 4 hours. (B) Western blotting of the HuNoV expressed in CFPS system by using different concentrations of plasmid template. M: marker, NC: negative control, PC: positive control. The mouse $6 \times$ His tag monoclonal primary antibody and HRP conjugated goat anti-mouse lgG (H $+\mathrm{L}$ ) secondary antibody were used to detect the target protein. (C) Dose-response curve of the protein yield to template concentration. The error bars indicated the standard deviation from triplicate biological samples. (D) Dynamic light scattering assay to characterize particle size distribution of HuNoV-VLPs. Sample expressed as intensity percentage. (E) Imaging of HuNoV-VLPs by using transmission electronic microscopy. Left column showed the results related to VP1-GII.3 and right column was the results related to VP1-Gll.4 in the CFPS system. 
BL21 extract, $6 \mu \mathrm{L}$ CK-T7 extract, and plasmid template harbouring the target gene. The extremely low endotoxin level of $E$. coli cell-free protein system could meet the demands for vaccine applications referencing guidelines for toxoid-based vaccines. ${ }^{21,22}$

We next used this CFPS system to synthesize two capsid proteins of HuNoV-VLPs: VP1 from HuNoV genotype GII.3 (VP1GII.3) and genotype GII.4 (VP1-GII.4). The VP1 capsid gene of HuNoV GII.3 or GII.4 was cloned into cell-free protein expression vector pIVEX2.4c, respectively. A $6 \times$ His-Tag was incorporated to the $\mathrm{N}$-terminus of the $\mathrm{P}$ domain to facilitate their detection and purification. Subsequently, the two plasmids containing HuNoV GII.3 or GII.4 VP1 gene were expressed in the CFPS system at $37{ }^{\circ} \mathrm{C}$ for 3 hours. The product was then analysed by western-blotting using a protocol that was previously developed. ${ }^{23,24}$ To optimize the protein production in the CFPS system, we generated a dose-response curve by using various concentrations (range from 5-25 ng $\mu^{-1}$ ) of plasmid template harbouring the HuNoV GII.3 or GII.4 VP1 gene. We used the "empty" CFPS without any template as our negative control and used the defined amount of GFP $\left(500 \mathrm{mg} \mathrm{L}^{-1}\right)$ as our positive control. The expression level of target protein was quantified by QuantityOne (Bio-Rad, USA). As shown in Fig. 1B, the size of recombinant protein synthesized in the CFPS system matched our expectations: molecular mass of $63 \mathrm{kDa}$ for VP1-GII.3 and 62 kDa for VP1-GII.4. GII.3 and GII.4 were produced at $0.62 \mathrm{~g} \mathrm{~L}^{-1}$ and $0.57 \mathrm{~g} \mathrm{~L}^{-1}$, respectively. Such protein yield is comparable to the cell-based system using P. pastoris. However, the production time is only 4 hours, which is much shorter than any cell-based system ( $>50$ hours).

We then examined if VLPs were formed from the capsid proteins synthesized by the CFPS system. To start, the product of CFPS reaction was centrifuged for $10 \mathrm{~min}$ to remove the debris. The supernatant was diluted five times by PBS buffer (pH 7.4) and concentrated by centrifugal filter units with $30 \mathrm{kDa}$ membrane (Millipore, USA). After buffer exchange for three times and high-speed centrifuge to remove the precipitate, the CFPS reaction was subjected to the morphological analysis. We used dynamic light scattering (DLS) to characterize the size distribution of the VLPs and electronic microscopy for VLP imaging. For DLS analysis, an aliquot was transferred to $400 \mu \mathrm{L}$ disposable sizing cuvettes and the diffusion of the particles moving under Brownian motion using a Zetasizer Nano-ZS (Malvern Instruments Ltd, UK) was measured. The particle sizes of VLPs were calculated as the average of three consecutive measurements recorded at $25{ }^{\circ} \mathrm{C}$. As shown in Fig. 1D, the average size of the VP1-GII.3 and VP1-GII.4 particles were $23.8 \mathrm{~nm}$ and $38.7 \mathrm{~nm}$, respectively. This discovery was consistent with previous reports, ${ }^{25}$ which found that the sizes of HuNoV-VLPs vary from 23-40 $\mathrm{nm}$. We also examined the morphology of HuNoV-VLPs via electronic microscopy as described previously. ${ }^{3,26}$ Basically, electron microscopy formvar carbon square grids (Electron Microscopy Sciences) were pretreated with $1 \%$ aqueous alcian blue for $5 \mathrm{~min}$. After three washes, $10 \mu \mathrm{L}$ of assembled VLPs of VP1-GII.3 and VP1-GII.4 were absorbed to the grids for $1 \mathrm{~min}$. The grids were stained with $3 \%$ phosphotungstic acid $\mathrm{pH} 7.0$ for $1 \mathrm{~min}$. The grid was then viewed with a JEOLJEM 1400 transmission electron microscopy. As shown in Fig. 1E, VLPs were formed from both the VP1-GII.3 and VP1-GII.4, which showed similar structures as reported previously. ${ }^{3,26}$ It is also worth mentioning that the different buffer systems might lead to different imaging of particle structure. ${ }^{27-30}$

It is worth mentioning that with the continuous decreasing cost of current CFPS system, the expense of HuNoV-VLPs when using CFPS system to produce could be reduced to $<5$ cents per $\mu \mathrm{L}$ with protein yields of $1.0 \mathrm{~g} \mathrm{~L}^{-1} \cdot{ }^{21}$ Assuming a similar dosage of NoV-VLPs as that of Takeda candidate VLP vaccine, which contains $100 \mu \mathrm{g}$ antigen per dose, the cost of 1 dose of HuNoVVLPs could be as low as \$2.5-5.0. Given the ease of the downstream purification process conferred by CFPS system, ${ }^{31}$ this platform could be a promising technology to produce both efficacious and affordable HuNoV vaccines.

\section{Conclusions}

In this study, we demonstrated that E. coli-based cell-free protein synthesis could be used to synthesize and assemble HuNoV VLPs. Compared to the cell-based system, our cell-free system led to similar protein yield but much shorter production time. This fast, high-yield system can be a promising manufacturing process for supplying $\mathrm{HuNoV}$ vaccines in the future.

\section{Notes and references}

1 S. G. Morillo and C. Timenetsky Mdo, Rev. Assoc. Med. Bras., 2011, 57, 453-458.

2 D. Flynn, Takeda's norovirus vaccine first to reach human trials, http://www.foodsafetynews.com/2016/06/takedasnorovirus-vaccine-first-to-reach-human-trials/\#.WNKSn_krJPY.

3 J. Tome-Amat, L. Fleischer, S. A. Parker, C. L. Bardliving and C. A. Batt, Microb. Cell Fact., 2014, 13, 134.

4 K. Ettayebi, S. E. Crawford, K. Murakami, J. R. Broughman, U. Karandikar, V. R. Tenge, F. H. Neill, S. E. Blutt, X. L. Zeng, L. Qu, B. Kou, A. R. Opekun, D. Burrin, D. Y. Graham, S. Ramani, R. L. Atmar and M. K. Estes, Science, 2016, 353, 1387-1393.

5 M. Tan, W. Zhong, D. Song, S. Thornton and X. Jiang, J. Med. Virol., 2004, 74, 641-649.

6 T. A. Lamounier, L. M. de Oliveira, B. R. de Camargo, K. B. Rodrigues, E. F. Noronha, B. M. Ribeiro and T. Nagata, Braz. J. Microbiol., 2015, 46, 1265-1268.

7 L. Santi, L. Batchelor, Z. Huang, B. Hjelm, J. Kilbourne, C. J. Arntzen, Q. Chen and H. S. Mason, Vaccine, 2008, 26, 1846-1854.

8 A. G. Diamos, S. H. Rosenthal and H. S. Mason, Front. Plant Sci., 2016, 7, 200.

9 S. Hervas-Stubbs, P. Rueda, L. Lopez and C. Leclerc, J. Immunol., 2007, 178, 2361-2369.

10 M. G. Casteleijn, A. Urtti and S. Sarkhel, Int. J. Pharm., 2013, 440, 39-47.

11 W. Guo, J. Sheng and X. Feng, Comput. Struct. Biotechnol. J., 2017, 15, 161-167. 
12 J. R. Mattingly Jr, J. Youssef, A. Iriarte and M. MartinezCarrion, J. Biol. Chem., 1993, 268, 3925-3937.

13 G. Yin and J. R. Swartz, Biotechnol. Bioeng., 2004, 86, 188195.

14 D. N. Hebert, J. X. Zhang and A. Helenius, Biochem. Cell Biol., 1998, 76, 867-873.

15 F. Katzen, G. Chang and W. Kudlicki, Trends Biotechnol., 2005, 23, 150-156.

16 Y. Endo and T. Sawasaki, Curr. Opin. Biotechnol., 2006, 17, 373-380.

17 T. Sawasaki, T. Ogasawara, R. Morishita and Y. Endo, Proc. Natl. Acad. Sci. U. S. A., 2002, 99, 14652-14657.

18 K. Jackson, R. Khnouf and Z. H. Fan, Methods Mol. Biol., 2014, 1118, 157-168.

19 P. Avenaud, M. Castroviejo, S. Claret, J. Rosenbaum, F. Megraud and A. Menard, Biochem. Biophys. Res. Commun., 2004, 318, 739-745.

20 M. C. Jewett and J. R. Swartz, Biotechnol. Bioeng., 2004, 86, 19-26.

21 K. Pardee, S. Slomovic, P. Q. Nguyen, J. W. Lee, N. Donghia, D. Burrill, T. Ferrante, F. R. McSorley, Y. Furuta, A. Vernet, M. Lewandowski, C. N. Boddy, N. S. Joshi and J. J. Collins, Cell, 2016, 167, 248-259.
22 L. A. Brito and M. Singh, J. Pharm. Sci., 2011, 100, 34-37.

23 T. Mahmood and P.-C. Yang, N. Am. J. Med. Sci., 2012, 4, 429434.

24 J. Sheng, H. Flick and X. Feng, Front. Microbiol., 2017, 8, 875.

25 J. L. Cuellar, F. Meinhoevel, M. Hoehne and E. Donath, J. Gen. Virol., 2010, 91, 2449-2456.

26 S. Lei, A. Ramesh, E. Twitchell, K. Wen, T. Bui, M. Weiss, X. Yang, J. Kocher, G. Li, E. Giri-Rachman, N. V. Trang, X. Jiang, E. P. Ryan and L. Yuan, Front. Microbiol., 2016, 7, 1699.

27 M. Fang, W. Diao, B. Dong, H. Wei, J. Liu, L. Hua, M. Zhang, S. Guo, Y. Xiao, Y. Yu, L. Wang and M. Wan, Intervirology, 2015, 58, 318-323.

28 S. F. Ausar, T. R. Foubert, M. H. Hudson, T. S. Vedvick and C. R. Middaugh, J. Biol. Chem., 2006, 281, 19478-19488.

29 A. Roldão, M. C. M. Mellado, J. C. Lima, M. J. T. Carrondo, P. M. Alves and R. Oliveira, PLoS Comput. Biol., 2012, 8, e1002367.

30 J. Nilsson, N. Miyazaki, L. Xing, B. Wu, L. Hammar, T. C. Li, N. Takeda, T. Miyamura and R. H. Cheng, J. Virol., 2005, 79, 5337-5345.

31 E. D. Carlson, R. Gan, C. E. Hodgman and M. C. Jewett, Biotechnol. Adv., 2012, 30, 1185-1194. 